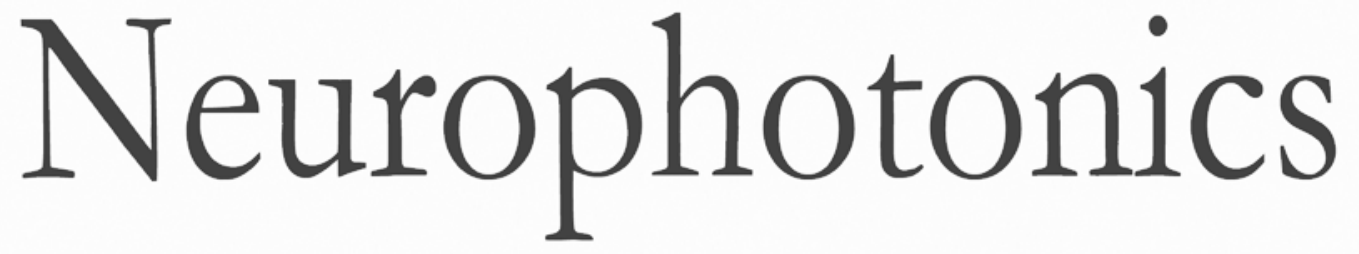

\title{
Functional near-infrared spectroscopy study on tonic pain activation by cold pressor test
}

Zeinab Barati

Issa Zakeri

Kambiz Pourrezaei 


\title{
Functional near-infrared spectroscopy study on tonic pain activation by cold pressor test
}

\author{
Zeinab Barati, ${ }^{a, t, *}$ Issa Zakeri, ${ }^{\mathrm{b}}$ and Kambiz Pourrezaei ${ }^{\mathrm{a}}$ \\ ${ }^{a}$ Drexel University, School of Biomedical Engineering, Science and Health Systems, Philadelphia, Pennsylvania, United States \\ ${ }^{b}$ Drexel University, Department of Epidemiology and Biostatistics, School of Public Health, Philadelphia, Pennsylvania, United States
}

\begin{abstract}
Functional near-infrared spectroscopy (fNIRS) has recently been suggested for monitoring cortical hemodynamic response to experimental and clinical acute pain. However, the hemodynamic response to a tonic, noxious cold stimulus, and its relation with subjective pain sensation is not fully characterized. We investigated the relationship between pain threshold and tolerance and the evoked hemodynamic response to cold pressor tests (CPTs) at varying intensities and explored the gender effect. Twenty-one healthy individuals (10 males and 11 females) performed four CPTs at $1^{\circ} \mathrm{C}, 5^{\circ} \mathrm{C}, 10^{\circ} \mathrm{C}$, and $15^{\circ} \mathrm{C}$. Deoxyhemoglobin $(\mathrm{HHb})$ and oxyhemoglobin $\left(\mathrm{HbO}_{2}\right)$ were measured continuously on the forehead by two "far" and two "near" channels in addition to pain scores, threshold, and tolerance. We found a significant within-subject correlation between pain threshold and the immediate $\mathrm{HbO}_{2}$ response at the right frontal region. Gender difference and asymmetrical activation were observed in the "far" channels but not the "near" channels, suggesting a hemispheric preference in response to noxious cold stimuli. No gender difference was found in pain threshold, tolerance, or scores. This research adds to the body of literature suggesting the use of fNIRS for bedside assessment of pain in addition to behavioral and subjective measures for comprehensive, multimodal pain management. ๑ 2017 Society of Photo-Optical Instrumentation Engineers (SPIE) [DOI: 10.1117/1.NPh.4.1.015004]
\end{abstract}

Keywords: gender difference; hemispheric asymmetry; hemodynamic response; linear mixed model; pain.

Paper 16056RRR received Aug. 12, 2016; accepted for publication Feb. 28, 2017; published online Mar. 20, 2017.

\section{Introduction}

Recent progress in brain imaging using advanced modalities such as positron emission tomography (PET) and functional magnetic resonance imaging (fMRI) revealed activation of brain regions during a physical or psychological experience of pain. ${ }^{1-6}$ Several studies have found a relationship between the intensity of perceived pain and the neuronal activation in several cortical areas. $^{3,7-11}$ While neuroimaging modalities exploring neural basis for nociception have advanced our understanding of the underlying mechanisms and have had great impact on basic science, they are not yet accepted for routine clinical examinations mainly due to the cost and limited accessibility.

Alternatively, functional near-infrared spectroscopy (fNIRS) has recently been suggested for monitoring cortical hemodynamic response to experimentally and clinically induced acute pain in adults and infants. ${ }^{12-28}$ fNIRS is an optical imaging tool for noninvasive, continuous monitoring of regional blood flow and tissue oxygenation. ${ }^{29-31}$ This imaging technique offers several advantages over other hemodynamic-based imaging techniques including being portable and noninvasive, no ionizing radiation or drug injection, measuring two hemodynamic parameters-deoxyhemoglobin ( $\mathrm{HHb}$ ) and oxyhemoglobin $\left(\mathrm{HbO}_{2}\right)$ - simultaneously, and relative robustness to motion artifact, which is desirable for the study of infants, small children, or elders with involuntary movement disorders.

To establish the suitability of fNIRS for bedside assessment of pain, it is essential to validate this technique using various noxious modalities and with different populations of patients. ${ }^{32}$

*Address all correspondence to: Zeinab Barati, E-mail: zbarati@alaska.edu

${ }^{\dagger}$ Current address: University of Alaska Fairbanks, Institute of Arctic Biology, Fairbanks, Alaska, United States
fNIRS studies of experimental models of pain in healthy adults have employed a variety of noxious stimuli, including hot plates, ${ }^{14,15,18}$ pressure, ${ }^{17}$ and electrical stimulus. ${ }^{16,19}$ However, the response to cold water stimulus is not well studied. Cold pressor pain, induced by submergence of the hand in cold water, is a well-validated test that is suggested to effectively mimic the pain of chronic diseases because of the higher level of unpleasantness that it evokes. ${ }^{33}$

We previously employed fNIRS to study the effect of repeated exposure to an ice water stimulus $\left(0^{\circ} \mathrm{C}\right)^{12}$ and showed that: (1) an ice water stimulus evoked robust and reproducible hemodynamic responses at both the skin and cortical levels; (2) the hemodynamic responses as well as the subjective pain rating scores reported after each stimulus adapted to repeated exposures; and (3) there was a significant within-subject correlation between the reported pain and the fNIRS signal. The objective of the present research was to identify the relationship between pain threshold and tolerance and the evoked hemodynamic response to cold pressor tests (CPTs) at varying intensities and to explore whether there is a gender effect. We employed CPT at variable temperatures of water and we hypothesized that subjective pain sensation is proportional to the amplitude of the evoked hemodynamic response at any given water temperature. Based on previous research reporting gender difference in pain sensation ${ }^{34}$ or hemodynamic activation, ${ }^{35-39}$ we speculated that tolerance to CPT and the associated evoked hemodynamic activation are lower in females.

\section{Materials and Methods}

Drexel University Institutional Review Board approved the protocols and procedures of this study. 


\subsection{Sample}

Twenty-one right-handed individuals of both sexes (10 males and 11 females) were recruited from the Drexel University community. Subjects claimed no history of neurological or psychological disorders nor use of any medication. They attended an orientation session at least one day prior to the actual experiment when they received detailed information on the experimental protocol and signed the informed consent. During orientation, subjects performed a CPT at $1^{\circ} \mathrm{C}$ in the real experimental setting to minimize anxiety associated with initial exposure to noxious cold water. Subjects were asked to refrain from smoking and drinking alcohol at least $3 \mathrm{~h}$ prior to the experiment.

\subsection{Procedure}

Four CPTs at different temperatures of water, i.e., $15^{\circ} \mathrm{C}, 10^{\circ} \mathrm{C}$, $5^{\circ} \mathrm{C}$, and $1^{\circ} \mathrm{C}$, were employed to generate low, moderate, and severe pain levels. Pioneering work on using CPT for pain study by Wolf and Hardy ${ }^{40}$ suggested that pain threshold to cold water is at $18^{\circ} \mathrm{C}$. Any decrease in water temperature is reported to be proportional to increase in pain score. The cold water temperatures in this research were chosen accordingly to induce different levels of pain.

For each trial of CPT, a baseline was recorded for $30 \mathrm{~s}$, then subjects were told to immerse their right hand up to the wrist in tepid water $\left(\sim 23^{\circ} \mathrm{C}\right)$ for $2 \mathrm{~min}$ for adaptation. Then, the experimenter verbally asked subjects to submerge the same hand in a constant temperature bath $\left(15^{\circ} \mathrm{C}, 10^{\circ} \mathrm{C}, 5^{\circ} \mathrm{C}\right.$, or $\left.1^{\circ} \mathrm{C}\right)$ for as long as they could tolerate the stimulated pain but no more than 5 min. During each experiment, numerical rating scales on a 0 to 10 scale (NRS-11) - where " 0 " indicates no pain and " 10 " indicates the worst imaginable pain-were recorded every $15 \mathrm{~s}$ in addition to pain threshold (when the first pain was felt) and tolerance (when the pain intensity became intolerable). ${ }^{41}$ There was at least half an hour rest period between trials. A block diagram of the protocol is shown in Fig. 1.

The cold and tepid water containers were equipped with commercial aquarium pumps to circulate water and minimize heat buildup around the immersed hand. The cold water container had a separate compartment for ice cubes to prevent any direct contact of the subject's skin with ice.

\subsection{Instrument}

fNIRS is an optical imaging modality that exploits visible light at NIR range $(650$ to $950 \mathrm{~nm})$, also termed the optical window. A photodetector placed at a certain distance from the light source detects the back-scattered light after it has passed a banana-shape pathway. The depth of light penetration is a function of the distance between the light source and photodetector (S-D): the larger the $\mathrm{S}-\mathrm{D}$, the deeper the light penetration. By choosing two appropriate S-Ds, one can sample absorption changes in a short pathway through superficial tissues and in a large pathway scanning deeper tissues within the head. Several theoretical and experimental studies have investigated depth-dependent changes in absorption using different S-D separations. ${ }^{42-44}$ We used two S-D separations: $1 \mathrm{~cm}$ ("near" channel) and $2.8 \mathrm{~cm}$ ("far" channel). Each probe had one "near" channel and two "far" channels. The "near" channel measured the hemodynamic response at the extracerebral layers while the "far" channels measured a superimposition of the hemodynamic changes within the extracerebral layers and the cortical tissue [Fig. 2(b)].

We employed the continuous wave fNIRS system (730 and $850 \mathrm{~nm}$ ) developed at Drexel University. ${ }^{45-47}$ Our fNIRS device had three main units: (1) two flexible fNIRS probes, each consisting of one multiwavelength light emitting diode and three photodetectors, (2) a control box for operating the hardware, and (3) a computer running the COBI Studio software ${ }^{48}$ for data acquisition and visualization. The two fNIRS probes were placed symmetrically on the subjects' forehead to measure relative changes in $\mathrm{HHb}$ and $\mathrm{HbO}_{2}$ throughout the experiment [Fig. 2(a)]. ${ }^{12}$ Although the "pain matrix" encompasses multiple regions of the cerebral cortex, we chose to study the frontal region because of the ease of measurements on the forehead.

\subsection{Data Analysis}

To eliminate high-frequency noise, respiration, and heart pulsation artifacts, raw intensity measurements were first filtered by a finite-impulse response low-pass filter with a cut-off frequency set to $0.14 \mathrm{~Hz}$, which was chosen based on the literature. ${ }^{49}$ Changes in the concentrations of $\mathrm{HHb}$ and $\mathrm{HbO}_{2}$ were calculated relative to the mean value of the optical intensity during the first $15 \mathrm{~s}$ of the prestimulus baseline recording. The $\mathrm{HHb}$ and $\mathrm{HbO}_{2}$ data were then smoothed using a spline basis expansion by imposing a penalty on the roughness of the second derivative of the data with a smoothing parameter $(\lambda)$ of 300 , which was chosen by visual judgment and prior knowledge of the process. ${ }^{50}$ An objective, data-driven method is also developed using the generalized cross-validation (GCV) measure ${ }^{51}$ and an optimum $\lambda$ minimizes $\operatorname{GCV}(\lambda)$ function plotted against $\log _{10} \lambda$. GCV is the most popular procedure for selecting an optimal value for the smoothing parameter. However, like other cross-validation methods, GCV tends to under-smooth the data. For this study, $\lambda$ was chosen empirically because the GCV plot resembled a sigmoid function which was not informative. ${ }^{52}$

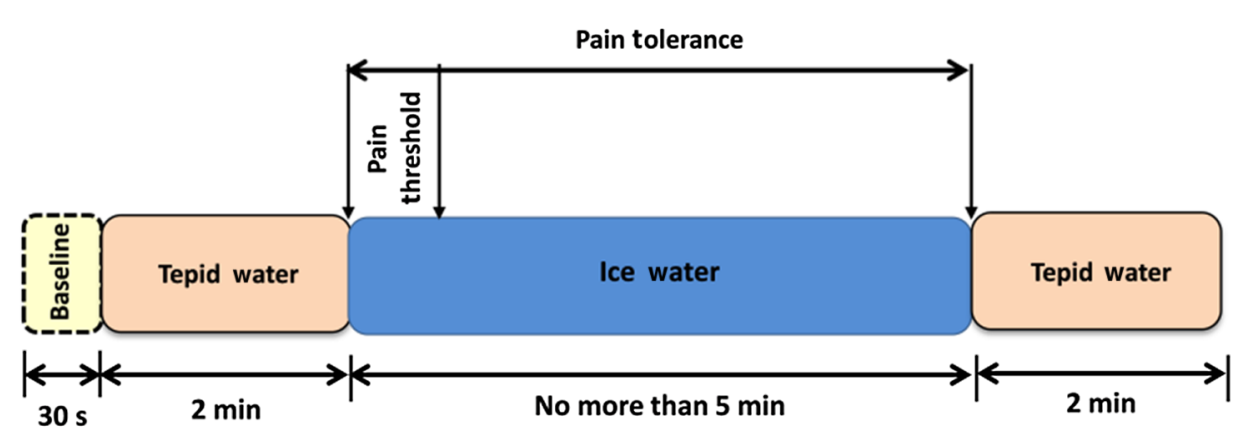

Fig. 1 Block diagram of the cold pressor protocol. 


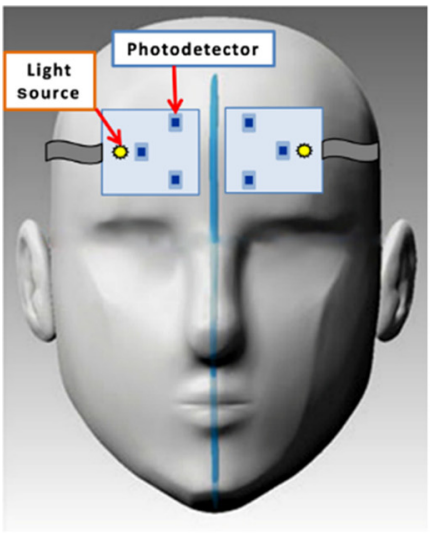

(a)

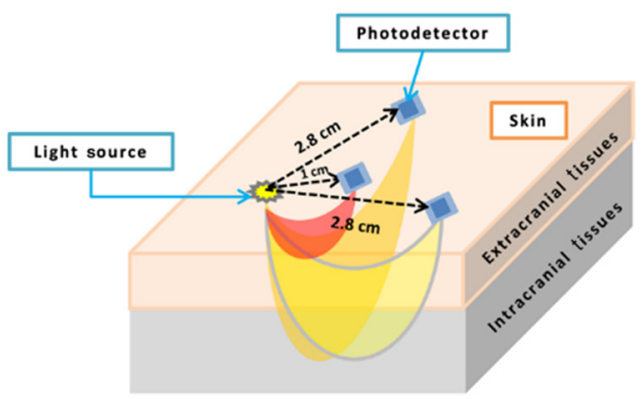

(b)

Fig. 2 The fNIRS probes. (a) A demonstration of the placement of fNIRS probes on a subject's forehead. The probes are shown reversed to illustrate the location of the light source and photodetectors. (b) A schematic of the fNIRS probe configuration. Photons travel from a light source to a photodetector through a banana-shape pathway with a penetration depth of half the source-detector distance. Measures are approximate. Reprinted with permission from Ref. 12.

Based on our previous study, ${ }^{12,52}$ we defined the following outcome measures: (1) the maximum change in $\mathrm{HHb}$ and $\mathrm{HbO}_{2}$ in response to a cold water stimulus, which may occur during or a few seconds after the stimulus, relative to the prestimulus value-hereafter referred to as $\Delta \mathrm{HHb}$ and $\Delta \mathrm{HbO}_{2} ;$ (2) maximum rate of change of $\mathrm{HbO}_{2}$ with respect to time, which occurs within a few seconds after hand immersion in cold water, calculated as the maximum value of the first derivative function-hereafter referred to as $\dot{m}\left(\mathrm{HbO}_{2}\right)$. This variable was not calculated for $\mathrm{HHb}$ due to the high variability of the response. We speculated that $\dot{m}\left(\mathrm{HbO}_{2}\right)$ variable is best associated with pain threshold as both variables are measured immediately after the hand immersion in cold water. $\mathrm{HHb}$ and $\mathrm{HbO}_{2}$ outcome measures of the two "far" channels for each probe were averaged.

We used linear mixed effects models for the statistical analysis of $\mathrm{HHb}$ and $\mathrm{HbO}_{2}{ }^{53,54}$ Linear mixed models provide a flexible and powerful approach for the analysis of repeated measures. Repeated measures data involve multiple observations on the same subject across a repeated factor, which is temperature here. These repeated measurements are likely to be correlated, therefore, any model fit requires parameter estimation of the covariance structure. Unlike classical repeated measures analysis of variance (ANOVA), which assumes the sphericity of the covariance matrix, linear mixed models allow a wide selection on the form of the variance-covariance matrix, which provides efficiency and flexibility. In a linear mixed model approach, the dependent variable is modeled as a combination of population characteristics, called fixed effects, and subject specific effects that are unique to a particular individual, called random effects. In our model, we included depth ("far" and "near"), side of the measurements (left and right), and gender as the fixed main effects and channel by side, channel by gender, and channel by side by gender as the interactions. We allowed different intercepts and slopes for individuals' regression lines across temperatures.

For subjective measures of pain, we analyzed the pain threshold, pain tolerance, and maximum pain score reported during the stimulus.

All signal processing calculations were performed in MATLAB (R2011a, MathWorks, Natwick, Massachusetts), and the smoothing was performed using the functional data analysis package for MATLAB ${ }^{50}$ Statistical analyses were conducted using the IBM SPSS Statistics 19. The significance criterion was $\alpha<0.05$ for all analyses. Post hoc pairwise comparisons were adjusted by Sidak criterion.

\section{Results}

\subsection{Subjective Reports of Pain}

Friedman's ANOVA by ranks revealed a significant difference in the median value of the pain threshold [Fig. 3(a)], tolerance [Fig. 3(b)], and maximum pain score [Fig. 3(c)] with respect to temperature $\left[\chi^{2}(3)=42.43, p\right.$-value $<0.001 ; \chi^{2}(3)=23.73$, $p$-value $<0.001$; and $\chi^{2}(3)=31.97, p$-value $<0.001$, respectively]. Post hoc Wilcoxon signed ranks tests adjusted by Bonferroni criterion yielded that:

1. Pain thresholds at $1^{\circ} \mathrm{C}$ and $5^{\circ} \mathrm{C}$ were not different but as the water temperature increased to $10^{\circ} \mathrm{C}$ and $15^{\circ} \mathrm{C}$, the pain threshold significantly increased as well.

2. Pain tolerance at $1^{\circ} \mathrm{C}$ was significantly lower than the tolerance at higher temperatures (i.e., $5^{\circ} \mathrm{C}, 10^{\circ} \mathrm{C}$, and $\left.15^{\circ} \mathrm{C}\right)$. No significant difference was found between tolerances at $5^{\circ} \mathrm{C}, 10^{\circ} \mathrm{C}$, and $15^{\circ} \mathrm{C}$.

3. Maximum pain score reported during the CPT decreased significantly with increase in water temperature.

We did not find any gender difference in the pain tolerance, pain threshold, or maximum pain score.

\section{2 $\mathrm{HHb}$ and $\mathrm{HbO}_{2}$}

Descriptive statistics of the outcome variables $\Delta \mathrm{HHb}, \Delta \mathrm{HbO}_{2}$, and $\dot{m}\left(\mathrm{HbO}_{2}\right)$ are provided in the Appendix. For $\mathrm{HbO}_{2}$, we found a three-way interaction between "gender, side, and depth (channel)" and a two-way interaction between "side and depth" (Table 1 and Fig. 4). A two-way interaction between "gender and depth" and significant main effects of temperature, side, and depth were found for $\mathrm{HHb}$ and $\mathrm{HbO}_{2}$, whereas a significant main effect of gender was found only for $\mathrm{HbO}_{2}$ (Table 1). 


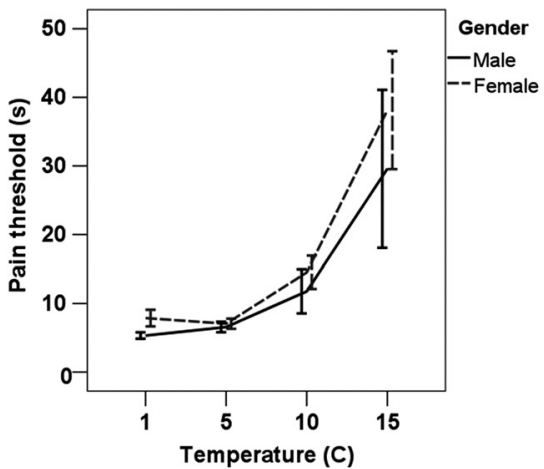

(a)

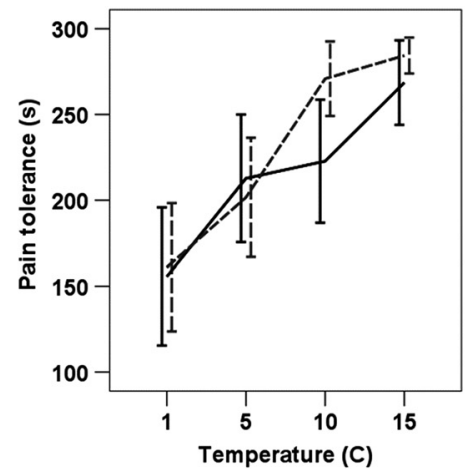

(b)

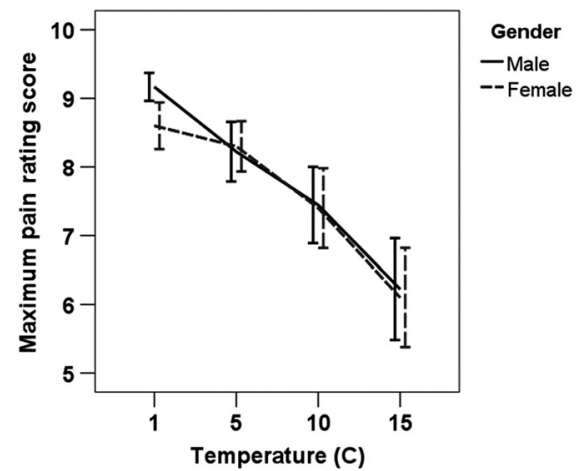

(c)

Fig. 3 The intensity of the cold stimulus adjusted by water temperature was proportional to the subjective measures of pain sensation: (a) pain threshold, (b) pain tolerance, (c) the maximum pain rating score reported during a CPT on a scale from 0 to 10 ( $n=21 ; 11$ females, 10 males).

Table 1 Statistics for the interactions and main effects for the outcome variables $\Delta \mathrm{HHb}, \Delta \mathrm{HbO}_{2}$, and $\dot{m}\left(\mathrm{HbO}_{2}\right)$. For the definition of the outcome variables, refer to Sec. 2.4 .

\begin{tabular}{|c|c|c|c|}
\hline & \multirow{2}{*}{$\begin{array}{c}\mathrm{HHb} \\
\Delta \mathrm{HHb}\end{array}$} & \multicolumn{2}{|c|}{$\mathrm{HbO}_{2}$} \\
\hline & & $\Delta \mathrm{HbO}_{2}$ & $\dot{m}\left(\mathrm{HbO}_{2}\right)$ \\
\hline Gender $\times$ side $\times$ depth & $F(2,242.65)=1.05, p=0.35$ & $F(2,254.21)=4.44, p=0.013$ & $F(2,253.60)=4.30, p=0.015$ \\
\hline Side $\times$ depth & $F(1,243.73)=0.74, p=0.39$ & $F(1,255.21)=27.55, p<0.001$ & $F(1,254.73)=17.64, p<0.001$ \\
\hline Gender $\times$ depth & $F(1,244.07)=8.20, p=0.005$ & $F(1,253.64)=8.77, p=0.003$ & $F(1,253.13)=17.40, p<0.001$ \\
\hline Temperature & $F(1,17.26)=13.67, p=0.002$ & $F(1,19.74)=8.01, p=0.01$ & $F(1,20.29)=21.81, p<0.001$ \\
\hline Side & $F(1,242.31)=6.85, p=0.009$ & $F(1,253.41)=15.16, p<0.001$ & $F(1,252.61)=18.91, p<0.001$ \\
\hline Depth & $F(1,244.04)=19.20, p<0.001$ & $F(1,253.61)=16.44, p<0.001$ & $F(1,253.12)=20.66, p<0.001$ \\
\hline Gender & $F(1,18.70)=1.36, p=0.26$ & $F(1,18.91)=4.28, p=0.05$ & $F(1,18.65)=5.68, p=0.03$ \\
\hline
\end{tabular}

\subsubsection{Gender difference}

Gender difference was observed at the "far" channels $(\Delta \mathrm{HHb}$ : $p$-value $=0.02$ for the right "far" channel; $\Delta \mathrm{HbO}_{2}: p$-value $=$ 0.001 for the right "far" channel and $\dot{m}\left(\mathrm{HbO}_{2}\right): p$-value $<$ 0.001 and 0.03 for the right and left "far" channels, respectively), whereas no gender difference was found at the "near" channels (Fig. 4). Moreover, males showed a depth-specific response (i.e., significantly different responses at the "far" and "near" channels) on the right side $\left[\Delta \mathrm{HHb}, \Delta \mathrm{HbO}_{2}\right.$, and $\dot{m}\left(\mathrm{HbO}_{2}\right): p$-value $\left.<0.001\right]$, whereas females did not.

\subsubsection{Asymmetrical response}

Asymmetrical hemodynamic activity was observed in $\mathrm{HHb}$ response for males $(\Delta \mathrm{HHb}: p=0.009)$ and in $\mathrm{HbO}_{2}$ for both genders $\left[\Delta \mathrm{HbO}_{2}: p\right.$-value $<0.001$ and $p$-value $=0.001$ for the males and females, respectively; $\dot{m}\left(\mathrm{HbO}_{2}\right): p$-value $<0.001$ and $p$-value $=0.008$ for the males and females, respectively] at the "far" channels, whereas no asymmetry was observed at the "near" channels.

\subsection{Correlation Analysis}

Correlation analysis revealed a statistically significant withinsubjects correlation between the pain threshold and $\dot{m}\left(\mathrm{HbO}_{2}\right)$ measured on the right side (right "near" channel: $R=0.44$, $p$-value $<0.05$, right "far" channel: $R=0.46, \quad p$-value $<$ $0.05)$. When calculated for males and females separately, the correlation was significant for males (right "near" channel: $R=$ $0.80, p$-value $<0.01$, right "far" channel: $R=0.77, p$-value $<$ 0.01 ) but not for females (right "near" channel: $R=0.40$, $t$-value $=1.30^{11}$, right "far" channel: $R=0.48, t$-value $=1.65^{11}$ ),

\section{Discussion}

In this fNIRS study, we investigated the relationship between subjective measures of pain-i.e., pain threshold and tolerance- and the evoked hemodynamic response to CPTs at varying intensities and explored the gender effect. We showed that pain threshold was significantly correlated with the immediate evoked hemodynamic response [i.e., $\dot{m}\left(\mathrm{HbO}_{2}\right)$ ]. We also found gender difference and asymmetry in the superimposed cortical and extracerebral hemodynamic response measured by "far" channels but not in the extracerebral hemodynamic activity.

Statistical analysis of the amplitude and rate of change of the evoked hemodynamic response yielded significant ipsilateral activation in the "far" channels, whereas no laterality was found in the "near" channels. This laterality suggests a hemispheric preference in response to noxious cold stimuli, which was unilateral to the stimulus. This finding is consistent with a PET study using CPT at $6^{\circ} \mathrm{C}$ (Ref. 1) where an ipsilateral 


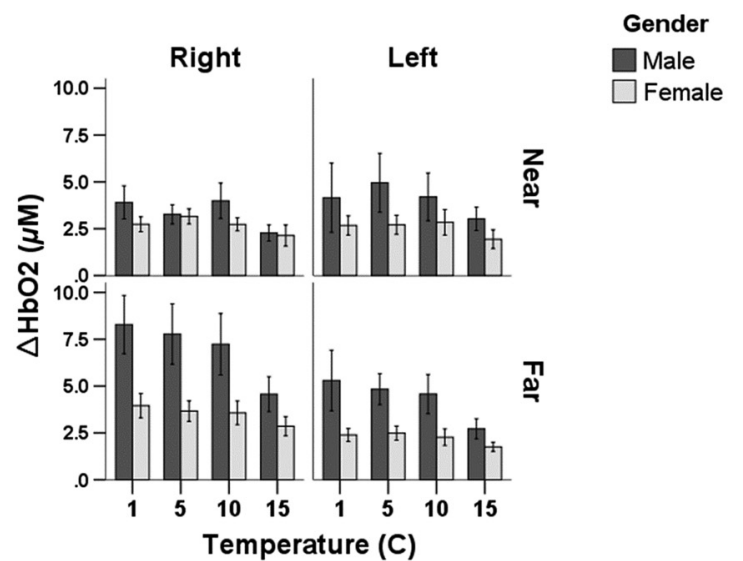

(a)

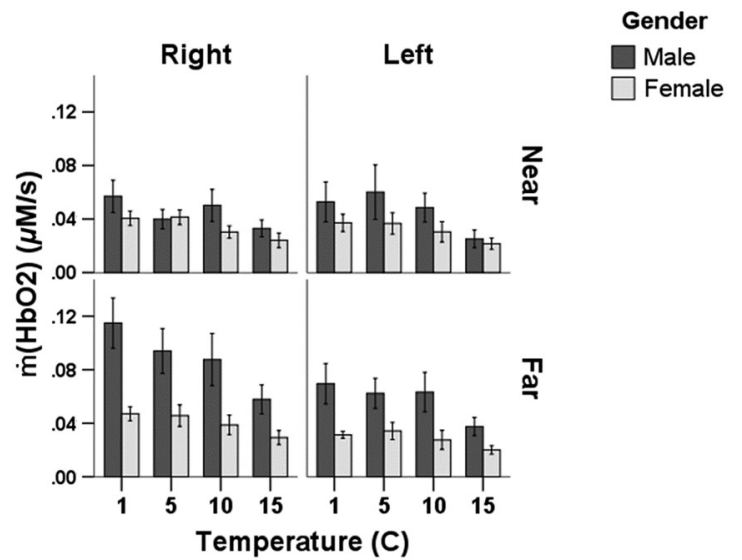

(b)

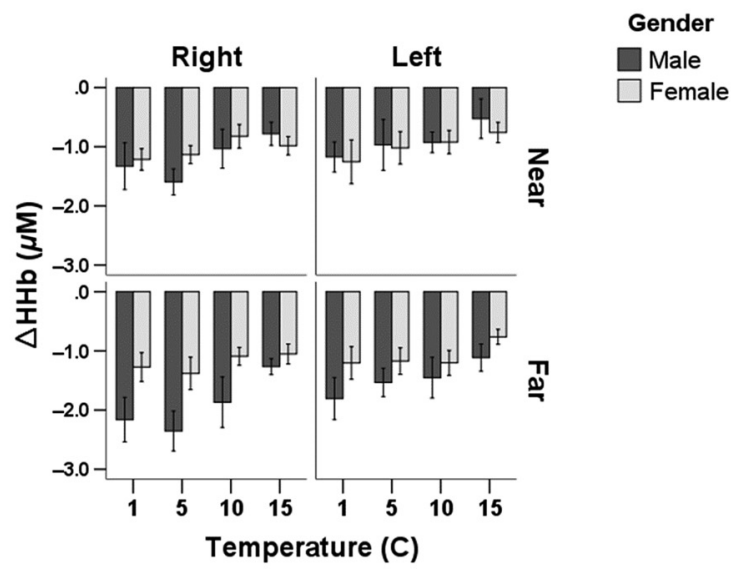

(c)

Fig. 4 Gender difference and asymmetrical hemodynamic activation was found at the "far" channels $(\mathrm{S}-\mathrm{D}=2.8 \mathrm{~cm})$ but not the "near" channels $(\mathrm{S}-\mathrm{D}=1 \mathrm{~cm})$ for (a) $\Delta \mathrm{HHb}$, (b) $\Delta \mathrm{HbO}_{2}$, and (c) $\dot{m}\left(\mathrm{HbO}_{2}\right) \quad(n=21 ; 11$ females, 10 males $)$. S-D stands for source-detector separation. See Sec. 2.4 for the definition of $\Delta \mathrm{HHb}, \Delta \mathrm{HbO}_{2}$, and $\dot{m}\left(\mathrm{HbO}_{2}\right)$.

increase in the regional cerebral blood flow in the lateral prefrontal cortex (Brodmann's areas 10 and 46) was observed. Also, an fMRI study showed bilateral prefrontal and ipsilateral dorsolateral prefrontal (DLPF) activation in response to hot and cold plates stimuli. ${ }^{5}$ It was reported that cold stimulus evoked larger brain regions and these two pain modalities (hot and cold) were significantly different in the frontal lobe. A ${ }^{133}$ Xe SPECT study of CPT, however, found contralateral increase of blood flow in the frontal lobe. ${ }^{55}$

We also showed gender difference at the "far" channels in response to painful cold stimulation with lower activation in females. Gender differences in cerebral activation in response to experimental and clinical noxious stimuli have been studied using advanced neuroimaging modalities. ${ }^{56-63}$ Despite identifying some gender differences in cerebral activation, there seems to be variability in activation and deactivation patterns across studies. The three following neuroimaging studies found gender difference in response to noxious stimuli in the prefrontal cortex. In an fMRI study, Moulton et al. ${ }^{60}$ discovered gender differences in BOLD signal in response to noxious contact heat stimuli. They observed that women show significantly more voxels with negative signal change than men in the primary somatosensory and DLPF cortices that may be in part explained by gender differences in baseline BOLD signal. In a PET study, Derbyshire et al. ${ }^{58}$ found significantly larger activation in males than females in response to equalized laser stimulation in several contralateral areas including prefrontal, primary, and secondary somatosensory cortices. Gender differences in medial prefrontal cortex activation in response to subthreshold and intense electrical stimulation were observed in an fMRI research showing a stronger activity in women. ${ }^{63}$ These studies and our research suggest that the prefrontal cortex may play an important role in mediating gender differences in the neurophysiological response to painful stimulation.

Moreover, we did not find any gender difference in the skin hemodynamic response. In addition, females did not show depthdependent activation. This may be justified by the much smaller cortical response in females. Thus, a larger sample size may be required to detect any depth-dependent response in females.

Another notable finding of this study was detecting a significant correlation between the pain threshold and the maximum rate of change in $\mathrm{HbO}_{2}$ response immediately after hand immersion in cold water measured on the right frontal region. The size of correlation was large for males and medium for females, which again may be explained by the smaller hemodynamic response in females.

The study of association between the trajectories of the hemodynamic response and the pain scores reported every $15 \mathrm{~s}$ is published elsewhere (Fig. 5). ${ }^{64}$ In summary, a pattern of adaptation of the hemodynamic response to the cold water 
CPT at $1^{\circ} \mathrm{C}$
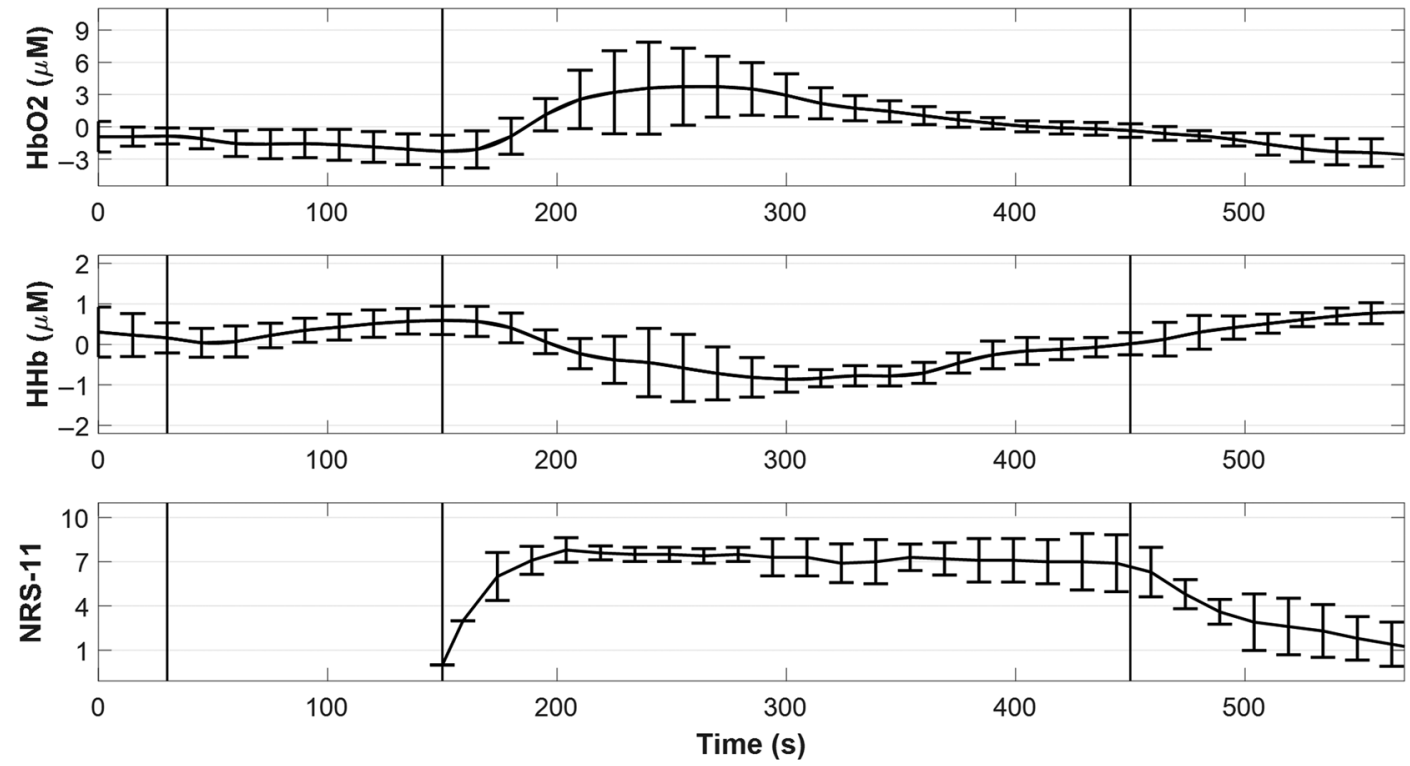

(a)
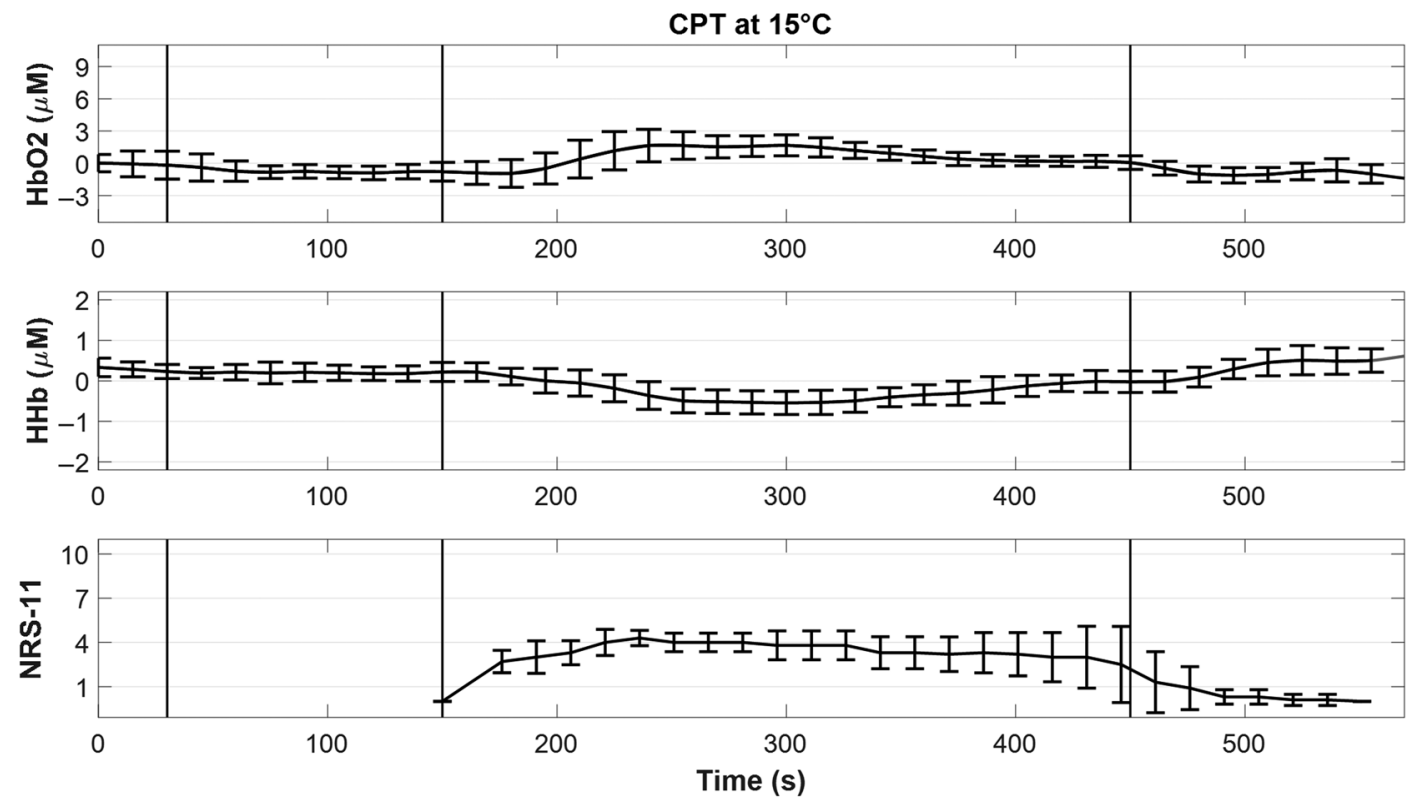

(b)

Fig. 5 The hemodynamic response $\left(\mathrm{HbO}_{2}\right.$ and $\left.\mathrm{HHb}\right)$ averaged for the two far channels on the right forehead and the numeric rating scales (NRS-11) reported every $15 \mathrm{~s}$ for the CPTs (CPT) at (a) $1^{\circ} \mathrm{C}$ and (b) $15^{\circ} \mathrm{C}$. The trajectories are averaged across eight subjects that could complete the CPTs at four temperatures $\left(1^{\circ} \mathrm{C}, 5^{\circ} \mathrm{C}, 10^{\circ} \mathrm{C}\right.$, and $\left.15^{\circ} \mathrm{C}\right)$ for the entire $5 \mathrm{~min}$. The black vertical lines from left to right represent hand immersion into tepid water, hand immersion into cold water, and hand immersion back into tepid water. Error bars represent standard deviation. Adapted from Ref. 64.

stimulus was seen for all temperatures; i.e., $\mathrm{HHb} / \mathrm{HbO}_{2}$ sharply decreased/increased upon hand immersion in cold water and after peaking at around $1 \mathrm{~min}$, they slowly increased/decreased to return to their prestimulus values. On the other hand, the subjective pain scores followed the evoked hemodynamic trajectory within the first minute of the CPT and then tended to remain around the peak value throughout the CPT.

\subsection{Caveats}

First, we understand that the cortical response to CPT is largely confounded by the extracerebral activation given the substantial systemic changes in the skin blood flow. The evoked hemodynamic response measured at the "near" channels is associated with the systemic blood flow changes in the extracerebral layers (e.g., skin and meninges), mainly due to task-induced changes in heart rate and blood pressure; whereas the response measured by the "far" channels is a superimposition of the skin and cortical hemodynamic activation. The origin of the evoked hemodynamic response at the cortical level is unknown to us since the nociceptive component and the autonomic aspect of the response are convoluted. We speculate that it originates from either the evoked local neurovascular coupling secondary to functional 
brain activity or the evoked systemic cerebral blood flow changes due to cardiovascular reactions such as heart rate and blood pressure variations.

Second, we used water stimulus at $15^{\circ} \mathrm{C}$, which is close to cold pain threshold, to elicit less autonomic response. However, our results showed significantly different responses at the skin and the cortex regardless of the water temperature. It seems that dissociation of the nociceptive and autonomic elements of response requires careful control of the experiment, e.g., by including innocuous challenges for autonomic arousal and then, isolating its response from the cortical nociceptive processing. In an effort to evoke a pure autonomic response, Harper et al. ${ }^{65}$ used the Valsalva maneuver and found significant activation in a number of brain regions including the medial and orbital prefrontal cortex that are activated in response to CPT as well. Their observation suggests that the evoked hemodynamic response to the CPTs in the prefrontal cortex may be due to autonomic nervous system activation. Thus, because cold noxious stimulus evokes substantial cardiovascular reaction, careful adjustment of the experiment's parameters is warranted to differentiate nociceptive processing and autonomic reaction to the CPT challenge.

Third, in our study, we could not find any gender difference in either the pain tolerance or the pain threshold; although gender difference in perception and expression of pain has been widely addressed in literature. ${ }^{66}$ Reports on gender differences in cold pain tolerance are more prevalent than cold pain threshold. Several studies have shown that women are more sensitive to cold pain than men are. A comprehensive survey of literature on gender differences in pain perception during 1998 to 2008 found that $80 \%$ of CPT studies showed that females tolerate significantly less pain than males. ${ }^{67}$ Another review noted that only one study (which included 15 male and 19 female participants) out of 23 did not show a gender difference in cold tolerance. ${ }^{66} \mathrm{It}$ is suggested that considering the moderate effect size of threshold and tolerance, a sample of 41 subjects for each gender group is needed to reach adequate power. ${ }^{68}$ We acknowledge that the sample size of our study was small (10 males, 11 females) thus, our study may lack enough power to catch the gender differences in cold pain tolerance which is reported in the literature. Nonetheless, since males and females' subjective reports of pain are comparable in our sample, it is plausible to compare their fNIRS signal under the condition of equivalent pain perception.

The observed gender difference in hemodynamic activation could be due to differences in anatomy, cortical processing, or autonomic regulation. There are some evidences for gender differences in the cerebral blood volume changes during a cognitive $\operatorname{task}^{39}$ and in the regulation of sympathetic nervous system. ${ }^{69}$ However, because we did not do any structural imaging or hormonal test, we cannot make any deterministic statement.

Finally, we did not have access to an automatic blood pressure recorder to monitor blood pressure during the CPTs. We ran similar analyses on the total hemoglobin $\left(\mathrm{HbO}_{2}+\mathrm{HHb}\right)$ and found the same results as $\mathrm{HbO}_{2}$, mainly because the amplitude of $\mathrm{HbO}_{2}$ response is considerably larger than $\mathrm{HHb}$ thus, the total hemoglobin response is vastly dominated by $\mathrm{HbO}_{2}$ response.

\subsection{Potential Applications and Future Direction}

fNIRS application for the assessment of pain is very recent but the literature shows a fast growing interest in such a novel solution. ${ }^{32}$ Under the assumption of reliable, self-reporting in healthy subjects, we can study the deviations of the discovered hemodynamic markers from normal values in case of an ailment or under influence of drugs such as morphine (e.g., morphine is shown to aggravate pain sensitization). At least four studies in adults ${ }^{20-22,70}$ and five studies in infants ${ }^{23-27}$ have used fNIRS in a clinical setting during a painful clinical intervention. It is crucial to report any pharmacologic treatments during experimental or clinical pain studies. For example, it has been reported that administration of morphine in critically ill infants was associated with significantly less changes in $\mathrm{HbO}_{2}$ compared with those who did not receive any analgesic medication. ${ }^{27}$ Gelinas et al. ${ }^{20}$ also reported that changes in regional oxygen saturation values during the insertion of intravenous line and arterial line were lower in patients who received morphine compared with those who did not. More studies with specific target populations such as elderly and cognitively impaired are needed to test the validity and reproducibility of fNIRS for pain assessment.

Some suggested applications of the technique proposed here include: (1) assessment of the preoperative sensitivity to CPT and its association with postoperative pain, ${ }^{71}$ (2) study of spontaneous pain under natural conditions like walking and talking, (3) examination of young children and elderly who would not stay still in a magnet or a PET scanner, (4) assessment of patients that are under heavy sedation or muscular blocking agents since the sedating agents significantly reduce pain behaviors, and (5) study of factors modulating the pain tolerance, such as long-term opioid use, drug abuse, smoking, and alcohol drinking. For instance, CPT has long been used to assess the opioid-induced hyperalgesia $(\mathrm{OIH}){ }^{72}$ The affordability and ease of use of fNIRS can provide a scheme for longitudinal monitoring of OIH development.

We suggest the use of fNIRS together with a complementary technique such as EEG for improving spatial and temporal resolutions, in addition to behavioral and subjective measures, for a comprehensive, multidimensional pain assessment. Although current fNIRS measurements are subjected to a number of limitations including low spatial resolution $(\sim 1 \mathrm{~cm})$, limited depth of penetration $(0.5$ to $2 \mathrm{~cm})$, and signal contamination by physiological noise, technical advancement in hardware and software may improve these factors in future. In particular, isolating the cortical response may help in developing neurofeedback frameworks that aim to design personalized treatments using an individual's own data for selfregulation. Techniques for separation of superficial hemodynamic response from the cortical activity are based on the assumption that responses measured by the near and far optodes are independent of each other; i.e., the near channel measures a global physiological inference which is independent of the task-evoked response measured by the far channel. This assumption is violated in the CPT as the task evokes a large systemic response in addition to a cortical nociceptive response. Further research is needed to address this important signal processing challenge.

Finally, the bilateral activation at the "far" and "near" channels observed in our study showed very similar trends of change through the time course of the experiment. Time-series analysis of fNIRS parameters was not conducted here. Given the fact that the autonomic response fairly quickly adapts to the stimulus while the pain perception may last for the entire duration of immersion, analysis of the dynamics of the hemodynamic response may unravel some interesting mechanisms. ${ }^{52}$ 


\section{Appendix}

Descriptive statistics of the outcome variables $\Delta \mathrm{HHb}, \Delta \mathrm{HbO}_{2}$, and $\dot{m}\left(\mathrm{HbO}_{2}\right)$ for different channels of the fNIRS and different temperatures of the CPTs are shown in Table 2. For the definition of the outcome variables, refer to Sec. 2.4. $N$ represents sample size, SD stands for standard deviation, and $95 \%$ CI represents $95 \%$ confidence interval.

Table 2

\begin{tabular}{|c|c|c|c|c|c|c|c|c|c|}
\hline $\begin{array}{l}\text { Hemodynamic } \\
\text { parameter }\end{array}$ & $\begin{array}{l}\text { Outcome } \\
\text { measure }\end{array}$ & Gender & $\begin{array}{c}\text { Water } \\
\text { temperature }\left({ }^{\circ} \mathrm{C}\right)\end{array}$ & $\begin{array}{l}\text { Forehead } \\
\text { side }\end{array}$ & Depth & $N$ & Mean & SD & $95 \% \mathrm{Cl}$ [LB UB] \\
\hline \multirow[t]{32}{*}{$\mathrm{HHb}$} & $\Delta \mathrm{HHb}$ & Males & 1 & Right & Near & 8 & -1.329 & 1.119 & {$[-2.264-0.394]$} \\
\hline & & & & & Far & 9 & -2.161 & 1.130 & {$[-3.030-1.293]$} \\
\hline & & & & Left & Near & 6 & -1.173 & 0.624 & {$[-1.828-0.518]$} \\
\hline & & & & & Far & 9 & -1.803 & 1.062 & {$[-2.619-0.987]$} \\
\hline & & & 5 & Right & Near & 6 & -1.594 & 0.539 & {$[-2.159-1.028]$} \\
\hline & & & & & Far & 7 & -2.353 & 0.893 & {$[-3.179-1.527]$} \\
\hline & & & & Left & Near & 8 & -0.969 & 1.214 & {$\left[\begin{array}{lll}-1.983 & 0.046\end{array}\right]$} \\
\hline & & & & & Far & 9 & -1.534 & 0.723 & {$[-2.090-0.978]$} \\
\hline & & & 10 & Right & Near & 5 & -1.033 & 0.735 & {$[-1.945-0.120]$} \\
\hline & & & & & Far & 9 & -1.867 & 1.282 & {$[-2.852-0.882]$} \\
\hline & & & & Left & Near & 7 & -0.925 & 0.461 & {$[-1.352-0.499]$} \\
\hline & & & & & Far & 10 & -1.452 & 1.088 & {$[-2.231-0.673]$} \\
\hline & & & 15 & Right & Near & 7 & -0.781 & 0.522 & {$[-1.264-0.298]$} \\
\hline & & & & & Far & 9 & -1.266 & 0.405 & {$[-1.577-0.954]$} \\
\hline & & & & Left & Near & 5 & -0.525 & 0.750 & {$\left[\begin{array}{lll}-1.457 & 0.406\end{array}\right]$} \\
\hline & & & & & Far & 9 & -1.113 & 0.688 & {$[-1.643-0.584]$} \\
\hline & & Females & 1 & Right & Near & 10 & -1.214 & 0.574 & {$[-1.624-0.804]$} \\
\hline & & & & & Far & 11 & -1.273 & 0.815 & {$[-1.821-0.726]$} \\
\hline & & & & Left & Near & 11 & -1.255 & 1.227 & {$[-2.079-0.430]$} \\
\hline & & & & & Far & 11 & -1.203 & 0.913 & {$[-1.817-0.590]$} \\
\hline & & & 5 & Right & Near & 10 & -1.133 & 0.480 & {$[-1.477-0.790]$} \\
\hline & & & & & Far & 11 & -1.379 & 0.907 & {$[-1.989-0.770]$} \\
\hline & & & & Left & Near & 10 & -1.019 & 0.867 & {$[-1.639-0.399]$} \\
\hline & & & & & Far & 10 & -1.172 & 0.709 & {$[-1.679-0.666]$} \\
\hline & & & 10 & Right & Near & 10 & -0.823 & 0.630 & {$[-1.274-0.373]$} \\
\hline & & & & & Far & 11 & -1.091 & 0.503 & {$[-1.429-0.753]$} \\
\hline & & & & Left & Near & 11 & -0.921 & 0.651 & {$[-1.358-0.483]$} \\
\hline & & & & & Far & 10 & -1.202 & 0.668 & {$[-1.680-0.724]$} \\
\hline & & & 15 & Right & Near & 8 & -0.983 & 0.439 & {$[-1.350-0.616]$} \\
\hline & & & & & Far & 10 & -1.052 & 0.534 & {$[-1.434-0.670]$} \\
\hline & & & & Left & Near & 9 & -0.759 & 0.516 & {$[-1.156-0.362]$} \\
\hline & & & & & Far & 9 & -0.762 & 0.381 & {$[-1.055-0.469]$} \\
\hline
\end{tabular}


Table 2 (Continued).

\begin{tabular}{|c|c|c|c|c|c|c|c|c|c|}
\hline $\begin{array}{l}\text { Hemodynamic } \\
\text { parameter }\end{array}$ & $\begin{array}{l}\text { Outcome } \\
\text { measure }\end{array}$ & Gender & $\begin{array}{c}\text { Water } \\
\text { temperature }\left({ }^{\circ} \mathrm{C}\right)\end{array}$ & $\begin{array}{l}\text { Forehead } \\
\text { side }\end{array}$ & Depth & $N$ & Mean & SD & $95 \% \mathrm{Cl}$ [LB UB] \\
\hline \multirow[t]{32}{*}{$\mathrm{HbO}_{2}$} & $\Delta \mathrm{HbO}_{2}$ & Males & 1 & Right & Near & 8 & 3.908 & 2.486 & [1.829 5.986] \\
\hline & & & & & Far & 10 & 8.284 & 4.912 & [4.770 11.798] \\
\hline & & & & Left & Near & 7 & 4.154 & 4.885 & {$[-0.364$ 8.671] } \\
\hline & & & & & Far & 9 & 5.300 & 4.853 & [1.569 9.030] \\
\hline & & & 5 & Right & Near & 7 & 3.269 & 1.356 & [2.015 4.523] \\
\hline & & & & & Far & 10 & 7.780 & 5.088 & [4.140 11.419] \\
\hline & & & & Left & Near & 8 & 4.954 & 4.440 & [1.242 8.666] \\
\hline & & & & & Far & 9 & 4.832 & 2.482 & [2.924 6.740] \\
\hline & & & 10 & Right & Near & 5 & 3.991 & 2.108 & [1.374 6.609] \\
\hline & & & & & Far & 9 & 7.231 & 4.923 & [3.447 11.015] \\
\hline & & & & Left & Near & 7 & 4.202 & 3.372 & [1.083 7.321$]$ \\
\hline & & & & & Far & 10 & 4.572 & 3.295 & [2.215 6.929] \\
\hline & & & 15 & Right & Near & 10 & 2.272 & 1.357 & [1.302 3.243] \\
\hline & & & & & Far & 9 & 4.570 & 2.795 & [2.422 6.718] \\
\hline & & & & Left & Near & 6 & 2.843 & 1.733 & [1.023 4.662] \\
\hline & & & & & Far & 10 & 2.721 & 1.687 & [1.514 3.928] \\
\hline & & Females & 1 & Right & Near & 9 & 2.739 & 1.192 & {$\left[\begin{array}{lll}1.823 & 3.655\end{array}\right]$} \\
\hline & & & & & Far & 11 & 3.955 & 2.154 & [2.508 5.402] \\
\hline & & & & Left & Near & 11 & 2.676 & 1.691 & {$\left[\begin{array}{lll}1.540 & 3.812\end{array}\right]$} \\
\hline & & & & & Far & 11 & 2.389 & 1.164 & [ 1.607 3.171] \\
\hline & & & 5 & Right & Near & 11 & 3.156 & 1.337 & [2.258 4.055] \\
\hline & & & & & Far & 11 & 3.664 & 1.814 & [2.446 4.883] \\
\hline & & & & Left & Near & 10 & 2.710 & 1.608 & {$\left[\begin{array}{lll}1.560 & 3.861\end{array}\right]$} \\
\hline & & & & & Far & 10 & 2.490 & 1.187 & [ 1.641 3.339] \\
\hline & & & 10 & Right & Near & 11 & 2.731 & 1.146 & {$\left[\begin{array}{lll}1.961 & 3.501\end{array}\right]$} \\
\hline & & & & & Far & 11 & 3.569 & 2.088 & [2.166 4.972] \\
\hline & & & & Left & Near & 10 & 2.844 & 2.143 & {$\left[\begin{array}{lll}1.311 & 4.377\end{array}\right]$} \\
\hline & & & & & Far & 10 & 2.270 & 1.392 & [1.274 3.266] \\
\hline & & & 15 & Right & Near & 9 & 2.138 & 1.693 & {$\left[\begin{array}{lll}0.836 & 3.439\end{array}\right]$} \\
\hline & & & & & Far & 10 & 2.859 & 1.618 & [1.702 4.017] \\
\hline & & & & Left & Near & 10 & 1.941 & 1.590 & [0.804 3.078] \\
\hline & & & & & Far & 10 & 1.756 & 0.779 & [1.198 2.314] \\
\hline
\end{tabular}


Table 2 (Continued).

\begin{tabular}{|c|c|c|c|c|c|c|c|c|c|}
\hline $\begin{array}{l}\text { Hemodynamic } \\
\text { parameter }\end{array}$ & $\begin{array}{l}\text { Outcome } \\
\text { measure }\end{array}$ & Gender & $\begin{array}{c}\text { Water } \\
\text { temperature }\left({ }^{\circ} \mathrm{C}\right)\end{array}$ & $\begin{array}{l}\text { Forehead } \\
\text { side }\end{array}$ & Depth & $N$ & Mean & SD & $95 \% \mathrm{Cl}$ [LB UB] \\
\hline & $\dot{m}\left(\mathrm{HbO}_{2}\right)$ & Males & 1 & Right & Near & 8 & 0.057 & 0.034 & {$\left[\begin{array}{lll}0.028 & 0.085\end{array}\right]$} \\
\hline & & & & & Far & 10 & 0.115 & 0.059 & [0.072 0.157$]$ \\
\hline & & & & Left & Near & 7 & 0.053 & 0.039 & {$\left[\begin{array}{lll}0.016 & 0.089\end{array}\right]$} \\
\hline & & & & & Far & 9 & 0.069 & 0.045 & {$\left[\begin{array}{lll}0.034 & 0.104\end{array}\right]$} \\
\hline & & & 5 & Right & Near & 7 & 0.040 & 0.019 & {$\left[\begin{array}{lll}0.022 & 0.058\end{array}\right]$} \\
\hline & & & & & Far & 10 & 0.094 & 0.053 & {$\left[\begin{array}{lll}0.056 & 0.132\end{array}\right]$} \\
\hline & & & & Left & Near & 8 & 0.060 & 0.057 & [0.012 0.108$]$ \\
\hline & & & & & Far & 9 & 0.062 & 0.034 & {$\left[\begin{array}{lll}0.036 & 0.088\end{array}\right]$} \\
\hline & & & 10 & Right & Near & 5 & 0.050 & 0.027 & {$\left[\begin{array}{lll}0.017 & 0.083\end{array}\right]$} \\
\hline & & & & & Far & 9 & 0.088 & 0.058 & {$\left[\begin{array}{lll}0.043 & 0.132\end{array}\right]$} \\
\hline & & & & Left & Near & 7 & 0.048 & 0.028 & [0.022 0.075$]$ \\
\hline & & & & & Far & 10 & 0.063 & 0.047 & {$\left[\begin{array}{lll}0.030 & 0.097\end{array}\right]$} \\
\hline & & & 15 & Right & Near & 10 & 0.033 & 0.020 & {$\left[\begin{array}{lll}0.019 & 0.047\end{array}\right]$} \\
\hline & & & & & Far & 9 & 0.058 & 0.033 & {$\left[\begin{array}{lll}0.033 & 0.083\end{array}\right]$} \\
\hline & & & & Left & Near & 6 & 0.025 & 0.016 & {$\left[\begin{array}{lll}0.008 & 0.042\end{array}\right]$} \\
\hline & & & & & Far & 10 & 0.037 & 0.021 & [0.022 0.053] \\
\hline & & Females & 1 & Right & Near & 9 & 0.040 & 0.016 & {$\left[\begin{array}{lll}0.028 & 0.053\end{array}\right]$} \\
\hline & & & & & Far & 11 & 0.047 & 0.017 & [0.035 0.059$]$ \\
\hline & & & & Left & Near & 11 & 0.037 & 0.022 & [0.023 0.052$]$ \\
\hline & & & & & Far & 11 & 0.031 & 0.008 & {$\left[\begin{array}{lll}0.026 & 0.037\end{array}\right]$} \\
\hline & & & $5^{\circ} \mathrm{C}$ & Right & Near & 11 & 0.041 & 0.018 & [0.029 0.054] \\
\hline & & & & & Far & 11 & 0.046 & 0.027 & {$\left[\begin{array}{lll}0.028 & 0.064\end{array}\right]$} \\
\hline & & & & Left & Near & 10 & 0.037 & 0.025 & [0.019 0.055] \\
\hline & & & & & Far & 10 & 0.034 & 0.020 & {$\left[\begin{array}{lll}0.020 & 0.049\end{array}\right]$} \\
\hline & & & 10 & Right & Near & 11 & 0.030 & 0.015 & [0.020 0.040] \\
\hline & & & & & Far & 11 & 0.039 & 0.024 & {$\left[\begin{array}{lll}0.023 & 0.055\end{array}\right]$} \\
\hline & & & & Left & Near & 10 & 0.030 & 0.024 & {$\left[\begin{array}{ll}0.013 & 0.048\end{array}\right]$} \\
\hline & & & & & Far & 10 & 0.027 & 0.022 & {$\left[\begin{array}{lll}0.011 & 0.044\end{array}\right]$} \\
\hline & & & 15 & Right & Near & 9 & 0.024 & 0.017 & {$\left[\begin{array}{lll}0.011 & 0.037\end{array}\right]$} \\
\hline & & & & & Far & 10 & 0.029 & 0.017 & {$\left[\begin{array}{lll}0.017 & 0.041]\end{array}\right]$} \\
\hline & & & & Left & Near & 10 & 0.022 & 0.013 & {$\left[\begin{array}{lll}0.012 & 0.031\end{array}\right]$} \\
\hline & & & & & Far & 10 & 0.020 & 0.010 & {$\left[\begin{array}{lll}0.013 & 0.027\end{array}\right]$} \\
\hline
\end{tabular}




\section{Disclosures}

Authors have no conflict of interest to disclose.

\section{Acknowledgments}

We would like to thank our lab research assistants at Drexel University, Kang Hee Lee, Rutvi Vyas, and Daryl OmireMayor for their help and support in data collection.

\section{References}

1. K. L. Casey et al., "Comparison of human cerebral activation pattern during cutaneous warmth, heat pain, and deep cold pain," $J$. Neurophysiol. 76(1), 571-581 (1996).

2. E. Disbrow et al., "Somatosensory cortex: a comparison of the response to noxious thermal, mechanical, and electrical stimuli using functional magnetic resonance imaging," Hum. Brain Mapp. 6(3), 150-159 (1998).

3. C. A. Porro et al., "Temporal and intensity coding of pain in human cortex," J. Neurophysiol. 80(6), 3312-3320 (1998).

4. F. Seifert and C. Maihofner, "Representation of cold allodynia in the human brain-a functional MRI study," NeuroImage 35(3), 11681180 (2007).

5. I. Tracey et al., "Noxious hot and cold stimulation produce common patterns of brain activation in humans: a functional magnetic resonance imaging study," Neurosci. Lett. 288(2), 159-162 (2000).

6. J. Brooks and I. Tracey, "From nociception to pain perception: imaging the spinal and supraspinal pathways," J. Anat. 207(1), 19-33 (2005).

7. L. Timmermann et al., "Differential coding of pain intensity in the human primary and secondary somatosensory cortex," J. Neurophysiol. 86(3), 1499-1503 (2001).

8. R. C. Coghill et al., "Pain intensity processing within the human brain: a bilateral, distributed mechanism," J. Neurophysiol. 82(4), 1934-1943 (1999).

9. M. N. Baliki et al., "Chronic pain and the emotional brain: specific brain activity associated with spontaneous fluctuations of intensity of chronic back pain," J. Neurosci. 26(47), 12165-12173 (2006).

10. S. W. Derbyshire et al., "Pain processing during three levels of noxious stimulation produces differential patterns of central activity," Pain 73(3), 431-445 (1997).

11. K. Bornhovd et al., "Painful stimuli evoke different stimulus-response functions in the amygdala, prefrontal, insula, and somatosensory cortex: a single-trial fMRI study," Brain 125(Pt 6), 1326-1336 (2002).

12. Z. Barati et al., "Hemodynamic response to repeated noxious cold pressor tests measured by functional near infrared spectroscopy on forehead," Ann. Biomed. Eng. 41(2), 223-237 (2013).

13. L. Becerra et al., "Brain measures of nociception using near infrared spectroscopy in patients undergoing routine screening colonoscopy," Pain 157, 840-848 (2015).

14. L. Becerra et al., "Diffuse optical tomography activation in the somatosensory cortex: specific activation by painful vs. non-painful thermal stimuli," PLoS One 4(11), e8016 (2009).

15. L. Becerra et al., "Diffuse optical tomography of pain and tactile stimulation: activation in cortical sensory and emotional systems," Neuroimage 41(2), 252-259 (2008).

16. M. A. Yucel et al., "Specificity of hemodynamic brain responses to painful stimuli: a functional near-infrared spectroscopy study," Sci. Rep. 5, 9469 (2015).

17. C. H. Lee et al., "Analysis for distinctive activation patterns of pain and itchy in the human brain cortex measured using near infrared spectroscopy (NIRS)," PLoS One 8(10), e75360 (2013).

18. A. Yennu et al., "A preliminary investigation of human frontal cortex under noxious thermal stimulation over the temporomandibular joint using functional near infrared spectroscopy," J. Appl. Biobehav. Res. 18, 134-155 (2013).

19. R. Re et al., "Multichannel time domain fNIRS mapping of cortical activation and superficial systemic responses during neuromuscular electrical stimulation," Proc. SPIE 8804, 880404 (2013).

20. C. Gelinas et al., "Toward a new approach for the detection of pain in adult patients undergoing cardiac surgery: near-infrared spectroscopya pilot study," Heart Lung 39(6), 485-493 (2010).
21. S. Viola et al., "Pathophysiology of migraine attack with prolonged aura revealed by transcranial Doppler and near infrared spectroscopy," Neurol. Sci. 31(Suppl. 1), S165-S166 (2010).

22. Y. Watanabe et al., "Monitoring cortical hemodynamic changes after sumatriptan injection during migraine attack by near-infrared spectroscopy," Neurosci. Res. 69(1), 60-66 (2011).

23. M. Bartocci et al., "Pain activates cortical areas in the preterm newborn brain," Pain 122(1-2), 109-117 (2006).

24. R. Slater et al., "Cortical pain responses in the infant brain," Pain 123(3), 332 (2006).

25. R. Slater et al., "How well do clinical pain assessment tools reflect pain in infants?" PLoS Med. 5(6), e129 (2008).

26. M. Ozawa et al., "Influence of repeated painful procedures on prefrontal cortical pain responses in newborns," Acta Pediatr. 100(2), 198-203 (2011).

27. M. Ranger et al., "A multidimensional approach to pain assessment in critically ill infants during a painful procedure," Clin. J. Pain 29(7), 613-620 (2013).

28. A. Pourshoghi et al., "Cerebral reactivity in migraine patients measured with functional near-infrared spectroscopy," Eur. J. Med. Res. 20, 96 (2015).

29. P. Rolfe, "In vivo near-infrared spectroscopy," Annu. Rev. Biomed. Eng. 2, 715-754 (2000).

30. A. Villringer and B. Chance, "Non-invasive optical spectroscopy and imaging of human brain function," Trends Neurosci. 20(10), 435442 (1997).

31. M. Ferrari and V. Quaresima, "A brief review on the history of human functional near-infrared spectroscopy (fNIRS) development and fields of application," NeuroImage 63(2), 921-935 (2012).

32. M. Ranger and C. Gélinas, "Innovating in pain assessment of the critically ill: exploring cerebral near-infrared spectroscopy as a bedside approach," Pain Manage. Nurs. 15, 519-529 (2012).

33. P. Rainville et al., "A psychophysical comparison of sensory and affective responses to four modalities of experimental pain," Somatosensory Motor Res. 9(4), 265-277 (1992).

34. B. Hellstrom and U. Lundberg, "Pain perception to the cold pressor test during the menstrual cycle in relation to estrogen levels and a comparison with men," Integr. Physiol. Behav. Sci. 35(2), 132-141 (2000).

35. H. Yang et al., "Gender difference in hemodynamic responses of prefrontal area to emotional stress by near-infrared spectroscopy," Behav. Brain Res. 178(1), 172-176 (2007).

36. T. Li, Q. Luo, and H. Gong, "Gender-specific hemodynamics in prefrontal cortex during a verbal working memory task by near-infrared spectroscopy," Behav. Brain Res. 209(1), 148-153 (2010).

37. K. Marumo et al., "Gender difference in right lateral prefrontal hemodynamic response while viewing fearful faces: a multi-channel nearinfrared spectroscopy study," Neurosci. Res. 63(2), 89-94 (2009).

38. J. Leon-Carrion et al., "Differential time course and intensity of PFC activation for men and women in response to emotional stimuli: a functional near-infrared spectroscopy (fNIRS) study," Neurosci. Lett. 403(1-2), 90-95 (2006).

39. M. Kameyama et al., "Sex and age dependencies of cerebral blood volume changes during cognitive activation: a multichannel near-infrared spectroscopy study," Neuroimage 22(4), 1715-1721 (2004).

40. S. Wolf and J. D. Hardy, "Studies on pain. Observations on pain due to local cooling and on factors involved in the "cold pressor" effect," J. Clin. Invest. 20(5), 521-533 (1941).

41. W. W. Downie et al., "Studies with pain rating scales," Ann. Rheum. Dis. 37(4), 378-381 (1978).

42. E. Okada et al., "Theoretical and experimental investigation of nearinfrared light propagation in a model of the adult head," Appl. Opt. 36(1), 21-31 (1997).

43. R. Saager and A. Berger, "Measurement of layer-like hemodynamic trends in scalp and cortex: implications for physiological baseline suppression in functional near-infrared spectroscopy," J. Biomed. Opt. 13(3), 034017 (2008)

44. H. Dehghani and D. T. Delpy, "Near-infrared spectroscopy of the adult head: effect of scattering and absorbing obstructions in the cerebrospinal fluid layer on light distribution in the tissue," Appl. Opt. 39(25), 47214729 (2000).

45. A. Bozkurt et al., "A portable near infrared spectroscopy system for bedside monitoring of newborn brain," Biomed. Eng. Online 4, 29 (2005). 
46. A. Bozkurt and B. Onaral, "Safety assessment of near infrared light emitting diodes for diffuse optical measurements," Biomed. Eng. Online 3, 9 (2004).

47. S. C. Bunce et al., "Functional near-infrared spectroscopy an emerging neuroimaging modality," IEEE Eng. Med. Biol. 25(4), 54-62 (2006).

48. H. Ayaz et al., "Using MazeSuite and functional near infrared spectroscopy to study learning in spatial navigation," J. Vis. Exp. 56, 3443 (2011).

49. A. Devaraj, Signal Processing for Functional Near-Infrared Neuroimaging, Drexel University, Pennsylvania, USA (2005).

50. J. O. Ramsay, G. Hooker, and S. Graves, Functional Data Analysis with $R$ and MATLAB, Springer, New York, USA (2009).

51. P. Craven and G. Wahba, "Smoothing noisy data with spline functions," Numer. Math. 31(4), 27 (1979).

52. Z. Barati, I. Zakeri, and K. Pourrezaei, "Functional data analysis view of functional near infrared spectroscopy data," J. Biomed. Opt. 18(11), 117007 (2013).

53. B. T. West, K. B. Welch, and A. T. Galecki, Linear Mixed Models: A Practical Guide Using Statistical Software, 1st ed., Chapman and Hall/ CRC (2006).

54. P. Diggle et al., Analysis of Longitudinal Data (Oxford Statistical Science Series), 2nd ed., Oxford University Press (2013).

55. V. Di Piero et al., "A cerebral blood flow study on tonic pain activation in man," Pain 56(2), 167-173 (1994).

56. S. M. Berman et al., "Sex differences in regional brain response to aversive pelvic visceral stimuli," Am. J. Physiol. 291(2), R268-R276 (2006).

57. L. A. Henderson, S. C. Gandevia, and V. G. Macefield, "Gender differences in brain activity evoked by muscle and cutaneous pain: a retrospective study of single-trial fMRI data," NeuroImage 39(4), 1867-1876 (2008).

58. S. W. Derbyshire et al., "Gender differences in patterns of cerebral activation during equal experience of painful laser stimulation," J. Pain 3(5), 401-411 (2002).

59. A. R. Hobson et al., "Real-time imaging of human cortical activity evoked by painful esophageal stimulation," Gastroenterology 128(3), 610-619 (2005).

60. E. A. Moulton et al., "Sex differences in the cerebral BOLD signal response to painful heat stimuli," Am. J. Physiol. 291(2), R257-R267 (2006).

61. B. D. Naliboff et al., "Sex-related differences in IBS patients: central processing of visceral stimuli," Gastroenterology 124(7), 1738-1747 (2003).

62. P. E. Paulson et al., "Gender differences in pain perception and patterns of cerebral activation during noxious heat stimulation in humans," Pain 76(1-2), 223-229 (1998).

63. T. Straube et al., "Sex differences in brain activation to anticipated and experienced pain in the medial prefrontal cortex," Hum. Brain Mapp. 30(2), 689-698 (2009).
64. Z. Barati et al., "Monitoring pain using functional near-infrared spectroscopy (fNIRS)," in Neurophotonics and Brain Mapping, Y. Chen and B. Kateb, Eds., p. 1048, CRC Press (2016).

65. R. M. Harper et al., "Lateralized and widespread brain activation during transient blood pressure elevation revealed by magnetic resonance imaging," J. Comp. Neurol. 417(2), 195-204 (2000).

66. R. B. Fillingim et al., "Sex, gender, and pain: a review of recent clinical and experimental findings," J. Pain 10(5), 447-485 (2009).

67. M. Racine et al., "A systematic literature review of 10 years of research on sex/gender and experimental pain perception — part 1: are there really differences between women and men?" Pain 153(3), 602-618 (2012).

68. J. L. Riley, 3rd et al., "Sex differences in the perception of noxious experimental stimuli: a meta-analysis," Pain 74(2-3), 181-187 (1998).

69. C. Hinojosa-Laborde et al., "Gender differences in sympathetic nervous system regulation," Clin. Exp. Pharmacol. Physiol. 26(2), 122-126 (1999).

70. F. Scholkmann and M. Wolf, "General equation for the differential pathlength factor of the frontal human head depending on wavelength and age," J. Biomed. Opt. 18(10), 105004 (2013).

71. T. Bisgaard et al., "Characteristics and prediction of early pain after laparoscopic cholecystectomy," Pain 90(3), 261-269 (2001).

72. M. Lee et al., "A comprehensive review of opioid-induced hyperalgesia," Pain Phys. 14(2), 145-161 (2011).

Zeinab Barati received her BS, MS, and PhD degrees in biomedical engineering from Tehran Polytechnic University, Iran University of Science and Technology, and Drexel University, respectively, and is currently a postdoctoral fellow at the University of Alaska Fairbanks. She was awarded a postdoctoral fellowship by the American Heart Association to study the autonomic regulation and cardiac side effects of an adenosine-based pharmacological agent for therapeutic hypothermia for the treatment of ischemic stroke.

Issa Zakeri received his MS degree in mathematics and his $\mathrm{PhD}$ in statistics from the University of Illinois at Urbana-Champaign. $\mathrm{He}$ is a professor in the Department of Epidemiology and Biostatistics, Drexel University, Philadelphia, Pennsylvania, USA. His principal areas of research are biostatistics, functional data analysis, longitudinal data analysis, multivariate analysis, time series analysis, sequential analysis, stochastic modeling, and applications of statistical and machine-learning methods to behavioral, biological, and medical sciences.

Kambiz Pourrezaei received his BS and MS degrees in electrical engineering from Tehran University and his $\mathrm{PhD}$ in electrical engineering from Rensselaer Polytechnic Institute, Troy, New York, USA. $\mathrm{He}$ is a professor in the School of Biomedical Engineering and Health Sciences, Drexel University, Philadelphia, Pennsylvania, USA. His research interests include bio-optics, bionanotechnology, and biomedical technology development. 